\title{
An Intelligent Sensor Based System for Real Time Heart Rate Monitoring (HRM)
}

\author{
Nusrat Jahan Farin, S. M. A. Sharif, Iftekharul Mobin \\ Department of Computer Science and Engineering, University of Liberal Arts Bangladesh (ULAB), Dhaka, \\ Bangladesh \\ Email: nusrat.farin.cse@ulab.edu.bd,sma.sharif.cse@ulab.edu.bd, iftekharul.mobin@ulab.edu.bd
}

Received 2 April 2016; accepted 23 May 2016; published 26 May 2016

Copyright (C) 2016 by authors and Scientific Research Publishing Inc.

This work is licensed under the Creative Commons Attribution International License (CC BY).

http://creativecommons.org/licenses/by/4.0/

(c) (i) Open Access

\begin{abstract}
A method and apparatus for monitoring heart rate of the heart using a wearable system is designed and implemented in this paper. A heart rate receives from heart beat signals and stores the data to a database and after a time period this method can determine an idle heart rate of the monitoring body. This idle heart rate is compared with the stored data and can determine the normal and abnormal heart rate variability. After the certain time period this system can detect the heart rate and also can send a signal to the user in time of abnormalities. Consequent estimations of heart rate variability are contrasted with this.
\end{abstract}

\section{Keywords}

Heart Rate, Micro-Controller, Heart Rate Monitor (HRM), Wearable System, Sensor Based System (SBS)

\section{Introduction}

Human health condition or heart rate recognition is very important technology for some patients to monitor them in a secure way. A number of motion-tracking or movement recognition technologies and health monitoring system have been developed for human motion capture in virtual reality and biomedical applications, including mechanical trackers, active magnetic trackers, optical tracking systems, acoustic, inertial/magnetic tracking systems, and health monitoring using smart sensors.

An intelligent self-controlled Micro-Controller Unit (MCU) based smart heart monitoring system is proposed in this paper. This system is mainly designed to monitor disable people, heart patients or any people who need to measure the heart rate. It takes input signals from ear-clip heart rate sensor placed in the monitored human body. 
And after collecting the values from the sensor those are saved in a database and after a time period for determining the idle heart rate the system starts to monitor the heart rate of the monitoring body and give message about the present condition of the monitoring body by using some algorithms.

A sensor based system is designed, implemented for monitoring human heart rate. Experimental result is demonstrated in this paper. The main target to develop this prototype is to track heart rate of human body and by analyzing the rate to determine a proper heart rate by using some algorithms and to provide an intensive care and support. Thus, it facilitates the monitoring committee to look after patients and ensure the security especially for the heart patient or disable people. To monitor the health condition wireless sensor is used in this system to detect the heartbeat rate and give alert in the time of abnormalities of heart beat. The sensors are attached with the sensor interfacing hardware prototyping board which is named as Arduino. For a certain time period the sensor data are collected from the human body using Arduino. Then the collected data is analyzed. This analysis provides automatic signal to the monitoring responsible authority and also the decision about the monitored people.

The real time Heart Rate Monitoring (HRM) system is an intelligent system assembled with a sensor and operated by Micro-Controller Unit (MCU) to monitor human heart rate status in real time. From the connected sensor embedded on the body, it takes reading of heart-beat. According to pre-defined logic and from resulting output, it determines the health condition. Similar approaches are disclosed before. But this system is incorporated for determining an ideal heart rate for a human body and also the present status of the heart rate by comparing with the ideal rate. Proposed system will make heart rate monitoring user friendly and low in cost. Finding of the study is that, this system perfectly demonstrates its efficiency and effectiveness in most of the cases.

Many researches are available for determining the heart rate, and heart rate monitoring system [1]. Some researches also make alarm on the abnormalities [2], to save heart rate data [3], to a database and show all data to the user of their system, and detect heart rate and the death reason on behalf of heart rate [4]. But no other system has the feature to save all the data collected from the monitoring body, save the data to a database, make an idle rate for the particular person and compare the heart rate with the idle one and make an alarm in the abnormal situation. So the proposed system in this paper is quite unique.

This paper is embodied as follows. We will explain the background study in Section 2. Next, we will describe the methods of the proposed prototype in Section 3 and then the experimental architecture and the results are shown in Section 4. Finally the paper is concluded in Section 5 and future scope will be described in Section 6.

\section{Study Background}

Embedded system for monitoring heart rate is a field for many researchers. There are many heart rate monitoring devices, applications and embedded systems are available. Many research exist for heart rate monitoring like as heart rate monitor apparatus [5]-[9], heart data monitoring method and apparatus [10], body area sensor networks: challenges and opportunities [11], respiration and heart rate monitoring apparatus [12], wireless sensor networks for personal health monitoring: Issues and an implementation [13], system architecture of a wireless body area sensor network for ubiquitous health monitoring [14], pulse monitor from magnetic apparatus [15], system for monitoring health, wellness and fitness [16], system for monitoring health, wellness and fitness having a method and apparatus for improved measurement of heat flow [17], apparatus for monitoring health, wellness and fitness [18], passive fetal heart rate monitoring apparatus and method with enhanced fetal heart beat discrimination [19] etc. Many researches are going on to determine the heart rate of human body. Middle-ware to support sensor network applications [20], Reliability and validity of the combined heart rate and movement sensor architecture [21], wearable sensor-based systems for health monitoring and prognosis [22] these system can determine the heart rate using the processor. Many researches also held on to determine the unambiguous health monitoring system such as-Person monitoring system [23], care system with alert mechanism [24], PDAbased physiological monitoring system for patient transport [25], home patient monitoring system [26], monitoring and reporting medical measurements [27], monitoring medical measurements [28] etc.

Our scheme is quite unique because no other system has database that can use to determine the idle heart rate for monitoring body and then can give the message in abnormal situations. None of the earlier heart rate apparatuses are altogether suitable for determine an idle heart rate for human body and can make warning itself in the situation of abnormalities. Our prototype is developed by using a ear-clip heart rate sensor embedded with Arduino [29]. In case of abnormal situation this prototype can demonstrate warning message for the monitoring body. 


\section{Methods}

\subsection{Overview of the System}

The aim of the system is to design and implement a system for monitoring heart rate, and to facilitate the continuous monitoring of people and determine a idle heart rate for the particular person and also provide the warning message in the abnormalities on the basis of the idle heart rate. Figure 1 shows architecture of the proposed system. This proposed system has mainly two different parts. One is sensor based unit and another is management based unit. Sensor based unit collect the physiological data from the monitoring body and the management unit store the data and show the real-time data of the monitoring body. The management unit is from either a local host network and show the result via monitor of the mobile phone or the laptop via WLAN or WiFi module.

The sensor based unit is design as follows: 1) it must be portable and must easier to carry 2) user friendly interface and also easy to use 3) it must collect all the heart rate of the monitoring body and must send to the database. On the other hand, the management unit is designed as follows: a) it must display the heart rate of the body b) it can store the sensor data c) it also display the graph of the hear rate d) it can retrieve and manage the information of the monitoring body e) it also connects with Internet to transmit data.

The transmission of data between a sensor based unit and the management unit is implemented by the client server model. In the proposed design, the sensor based unit serves as the client and the management unit act as server end. Communication depends on the Internet protocol for accurate data transmission.

\subsection{Flowchart}

Figure 2 shows the flowchart view of the system. At first when the system start to work the using sensor starts to collect data from the monitoring body. Then it saves all the data to a database through WLAN or WiFi module. Then the proposed system set a threshold value to determine an idle heart rate rate of the body. Then it automatically analyzing the data and show the results. Then collecting data then compare with the idle threshold value and if their occur any abnormalities then it gives an alarm to the user of the system.

\subsection{Sensor Based Unit}

For the unit of sensor based the ear-clip heart rate sensor is used for monitoring the heart rate. This sensor take heart beat as an analog signal and sent it to the database. It sense the real time heart rate of the monitoring body. For monitoring it sends all the collected data to the management unit to show the results. The used sensor is connected with a micro-controller named as arduino uno. All data goes from the sensor to the database through its WLAN device via the arduino. Circuit diagram of the proposed system is given in Figure 3.

\subsection{Management Unit}

Figure 1 shows the management unit. Sensor data collected from the monitoring body through sensor and store and retrieve data from the database. Management unit process the data from and show the result to the user. The

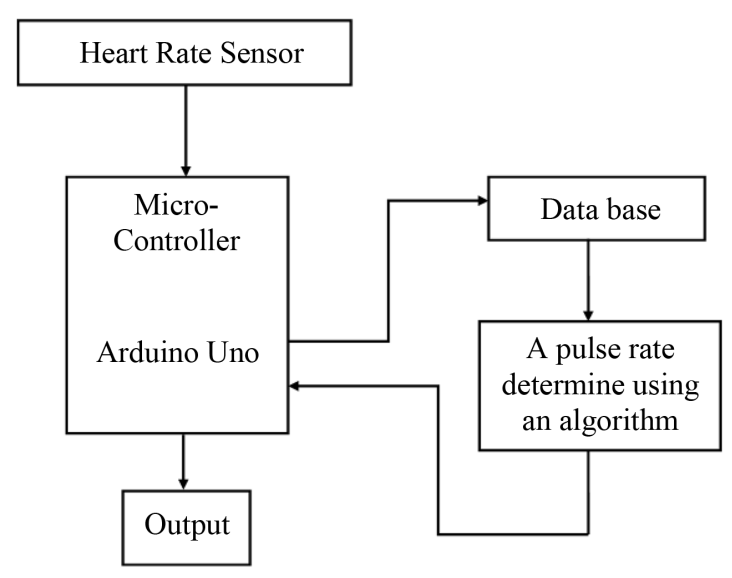

Figure 1. Sensor based and management unit. 


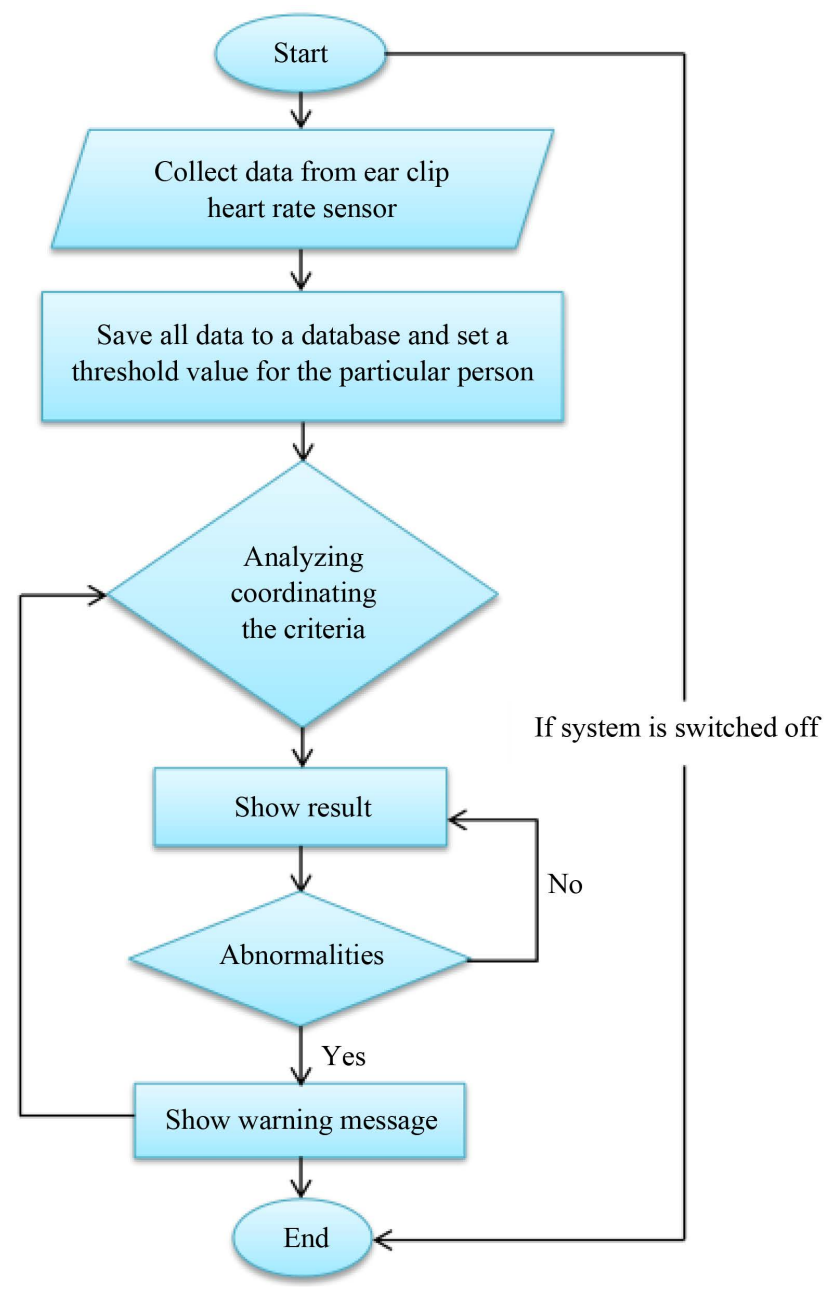

Figure 2. Flow chart of the system overview.

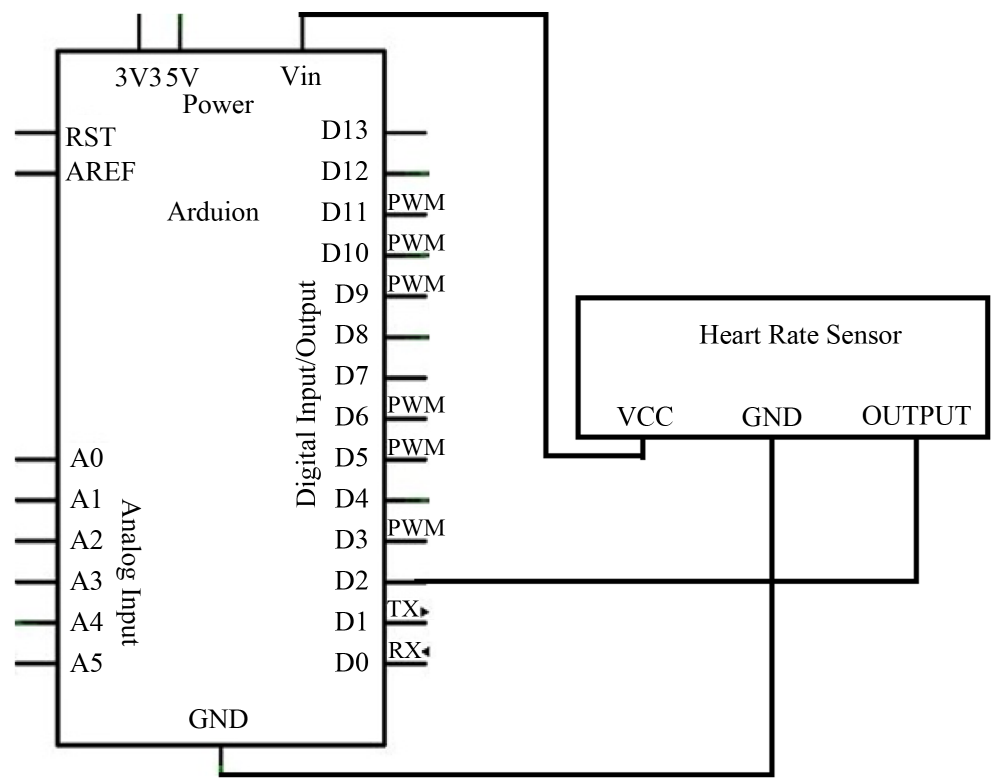

Figure 3. Circuit diagram of the system. 
system must collect a large number of data from the monitoring body for a time period to process the data. Then the system process the data using a predefined algorithm. This unit also show the heart rate and set an idle heart rate for the monitoring body using the algorithm. Sometimes the heart rate goes up or down than the idle heart rate and at that time it can create an alarm or give an warning message to the monitoring people. Now the system shows the result in a monitor like laptop or mobile phone. It also generates warning message to the laptop.

\section{Experiment}

\subsection{Circuit Diagram}

Figure 3 Circuit diagram shows that how the arduino board connected with the ear-clip heart rate sensor. Arduino board has some digital and analog pin. To get the output from the sensor the output pin of the ear-clip heart rate sensor is connected with the digital pin 2 of the arduino. The power supply and ground pin is connect with the the vcc and gnd pin of the arduino.

\subsection{Experimental Environment}

The proposed system is an web-based human Heart Rate Monitoring system (HRM) which is implemented on an embedded system with arduino and ear-clip heart rate sensor. The server side system ran the apache web server, PHP language and MySQL database and the sensor data read from the sensor using arduino code. This section describes the implementation of web-based human heart rate monitoring system, and demonstrates the performance of the proposed system and determine the idle heart rate for the monitoring body and make an alert in an abnormal situation. The environment of the experiment how the sensor and arduino board connected with the body shown in Figure 4.

\subsection{Architecture of the Proposed Prototype}

Figure 5 shows the system overview how the proposed prototype work. For determining the systems perfectness data collect from 10 different persons and shown in Figure 6. First the sensor which connected with arduino and the WLAN or WiFi is placed to the monitoring body. The sensor started to collect the data and it send the data to a web server using WLAN or WiFi module. Then an algorithm is determined to analyzing the data. For the proposed prototype we use an algorithm of an average which is predefined in arduino. After that it determined an idle heart rate. The the heart rate rate of the monitoring body is shown in the monitor and it may send the data to the physician. In the case of abnormalities the system can make a signal to the user such as he/ she is in abnormal situation.

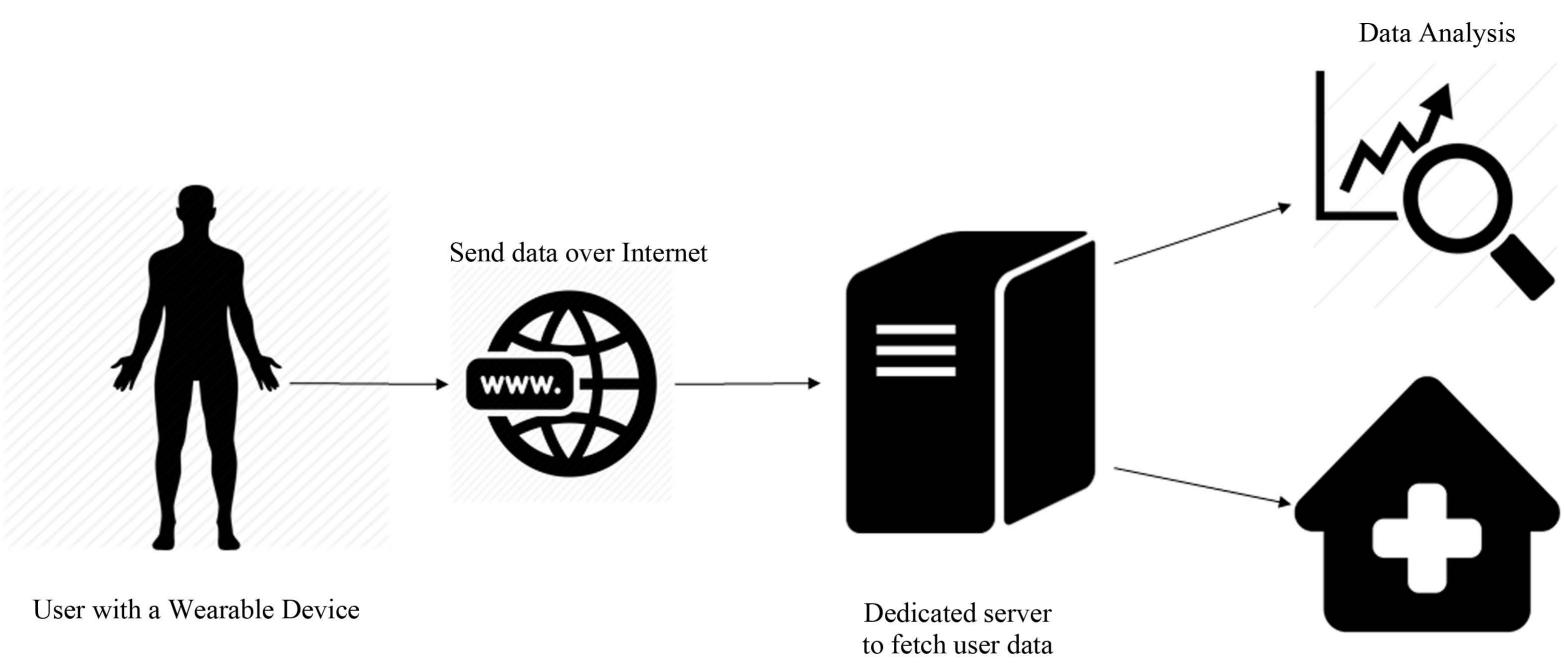

Send data to user/ Physician

Figure 4. Architecture of the overall proposed prototype. 


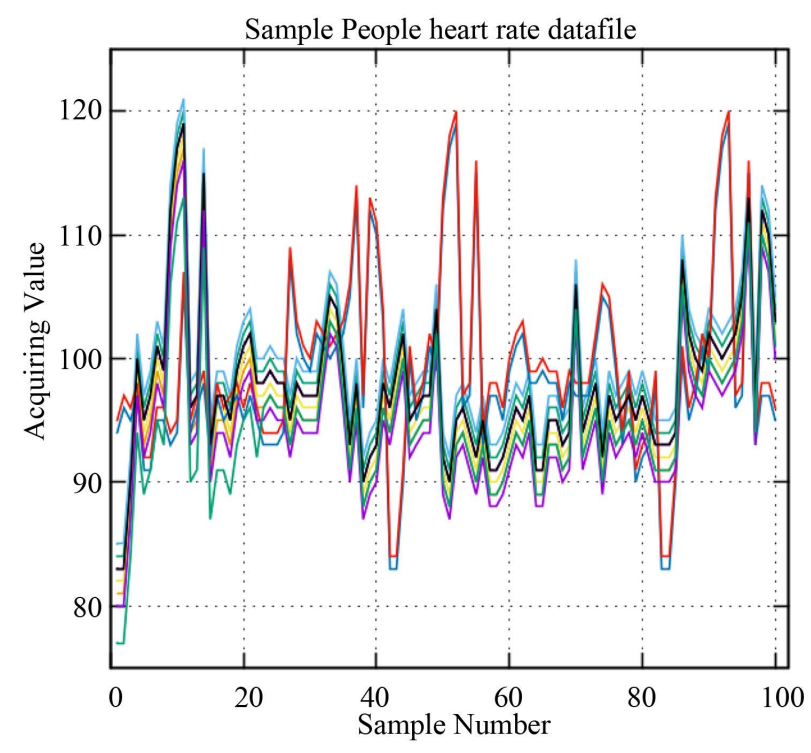

Figure 5. Heart beat signal sense from sampling person (10 people).

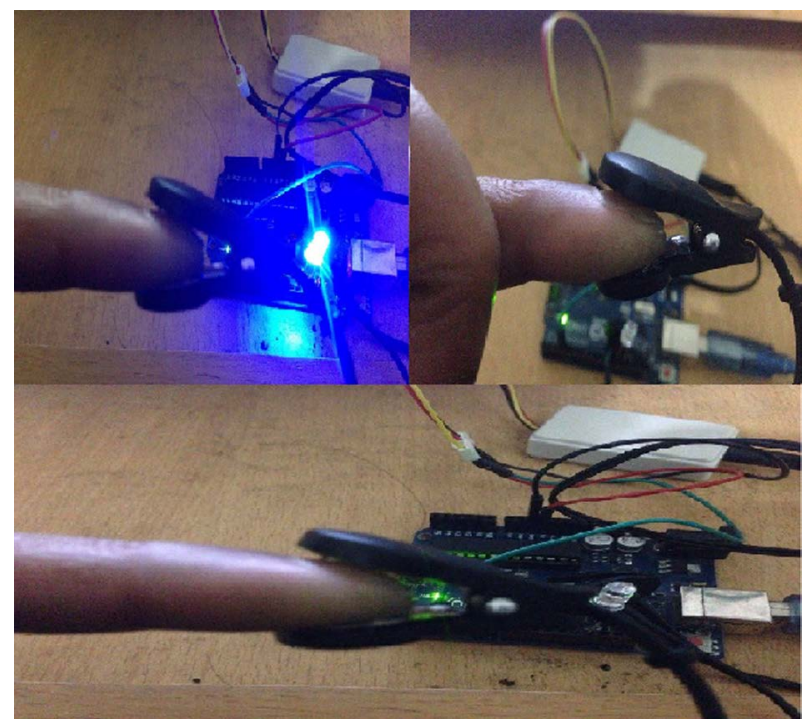

Figure 6. Experimental environment.

\subsection{Results}

To determine whether the proposed prototype work perfectly or not 10 person of different age is selected to take their heart rate from the finger of the hand. This study measure the idle heart rate for each of the monitoring people and compare their further heart rate with the idle one and make an alert in the abnormalities. Though all the sampling people are almost healthy so in the experimental time it does not need to make any alert. The aim of this experiment is to determine whether the system work perfectly or not. Figure 6 shows the results of the experiment in different body of several time. For the proposed prototype we take 10 person for the experiment. We find different types of heart rate data for different people. Each and every time our prototype can able to determine the idle heart rate and also can compare the heart rate with the idle one.

\section{Conclusion}

In this paper the system is implemented successfully. In most of the cases the system behaves quite nice. Heart 
Rate Monitoring (HRM) system is a simple solution for real time heart rate status monitoring and abnormality alerting. By using this system we can determine the idle heart rate for each and every person and can monitor them in a nice way. This system is also very user friendly. Moreover, HRM is a complete solution for real time heart rate monitoring and creates an emerging awareness in a secure way.

\section{Future Scope}

In this paper we deal with the numeric data which is found from our experiment that helps to detect the agents health condition as well as heart rate. We will co-relate the sensor data with the real patients data which will help us to compare the real scenario. In future we will add some other features to develop the system and make it easy to user through smart application. This system can be incorporated with cloud computing and enriched the prototype system. This noble system can be used for disabled or patient to aware about their present situation.

\section{References}

[1] Achten, J. and Jeukendrup, A.E. (2003) Heart Rate Monitoring. Sports Medicine, 33, 517-538. http://dx.doi.org/10.2165/00007256-200333070-00004

[2] Beinlich, I.A., Suermondt, H.J., Chavez, R.M. and Cooper, G.F. (1989) The ALARM Monitoring System: A Case Study with Two Probabilistic Inference Techniques for Belief Networks. Springer, Berlin.

[3] Deanfield, J.E., Selwyn, A.P., Chierchia, S., Maseri, A., Ribeiro, P., Krikler, S. and Morgan, M. (1983) Myocardial Ischaemia during Daily Life in Patients with Stable Angina: Its Relation to Symptoms and Heart Rate Changes. The Lancet, 322, 753-758. http://dx.doi.org/10.1016/S0140-6736(83)92295-X

[4] Jouven, X., Empana, J.-P., Schwartz, P.J., Desnos, M., Courbon, D. and Ducimetière, P. (2005) Heart-Rate Profile during Exercise as a Predictor of Sudden Death. New England Journal of Medicine, 352, 1951-1958. http://dx.doi.org/10.1056/NEJMoa043012

[5] Armstrong, D.R. and Van Eck, H.J.R. (1997) Heart Monitoring Apparatus. US Patent 5606978.

[6] Christopher, S., Muessig, D., Lefkov, S. and Orlov, M.V. (2011) Heart Monitoring Apparatus. US Patent 7985185.

[7] Crockford, C. (2013) Heart Monitoring Apparatus. US Patent App. 13/886,541.

[8] Gamlyn, L., O’Sullivan, S., Needham, P. and Harris, T. (1998) Heart Monitoring Apparatus and Method. US Patent 5749367.

[9] Steinhaus, B.M., Vance, F.I., Curtis, A. and Koestner, K. (1992) Heart Rejection Monitoring Apparatus and Method. US Patent 5139028.

[10] Digby, D. and Homayoun, H. (1990) Heart Data Monitoring Method and Apparatus. US Patent 4958641.

[11] Hanson, M.A., Powell Jr., H.C., Barth, A.T., Ringgenberg, K., Calhoun, B.H., Aylor, J.H. and Lach, J. (2009) Body Area Sensor Networks: Challenges and Opportunities. Computer, 1, 58-65. http://dx.doi.org/10.1109/MC.2009.5

[12] Manus, E.A. and Wiley, P.H. (1986) Respiration and Heart Rate Monitoring Apparatus. US Patent 4576179.

[13] Milenković, A., Otto, C. and Jovanov, E. (2006) Wireless Sensor Networks for Personal Health Monitoring: Issues and an Implementation. Computer Communications, 29, 2521-2533. http://dx.doi.org/10.1016/j.comcom.2006.02.011

[14] Otto, C., Milenkovic, A., Sanders, C. and Jovanov, E. (2006) System Architecture of a Wireless Body Area Sensor Network for Ubiquitous Health Monitoring. Journal of Mobile Multimedia, 1, 307-326.

[15] Poh, M.-Z., Swenson, N.C. and Picard, R.W. (2010) Motion-Tolerant Magnetic Earring Sensor and Wireless Earpiece for Wearable Photoplethysmography. IEEE Transactions on Information Technology in Biomedicine, 14, 786-794. http://dx.doi.org/10.1109/TITB.2010.2042607

[16] Teller, E., Stivoric, J.M., Kasabach, C.D., Pacione, C.D., Moss, J.L., Liden, C.B. and McCormack, M.A. (2003) System for Monitoring Health, Wellness and Fitness. US Patent 6605038.

[17] Stivoric, J.M., Moss, J.L., Kasabach, C.D., Boehmke, S.K., Zaremsky, M. and Sica, V. (2003) System for Monitoring Health, Wellness and Fitness Having a Method and Apparatus for Improved Measurement of Heat Flow. US Patent 6595929.

[18] Teller, E., Stivoric, J.M., Kasabach, C.D., Pacione, C.D., Moss, J.L. and Liden, C.B. (2007) Apparatus for Monitoring Health, Wellness and Fitness. US Patent 7261690.

[19] Zahorian, S.A., Livingston, D.L. and Pretlow III, R.A. (1996) Passive Fetal Heart Rate Monitoring Apparatus and Method with Enhanced Fetal Heart Beat Discrimination. US Patent 5524631. 
[20] Brage, S., Brage, N., Franks, P.W., Ekelund, U. and Wareham, N.J. (2005) Reliability and Validity of the Combined Heart Rate and Movement Sensor Actiheart. European Journal of Clinical Nutrition, 59, 561-570. http://dx.doi.org/10.1038/sj.ejcn.1602118

[21] Heinzelman, W.B., Murphy, A.L., Carvalho, H.S. and Perillo, M.A. (2004) Middleware to Support Sensor Network Applications. IEEE Network, 18, 6-14. http://dx.doi.org/10.1109/MNET.2004.1265828

[22] Pantelopoulos, A. and Bourbakis, N.G. (2010) A Survey on Wearable Sensor-Based Systems for Health Monitoring and Prognosis. IEEE Transactions on Systems, Man, and Cybernetics, Part C: Applications and Reviews, 40, 1-12. http://dx.doi.org/10.1109/TSMCC.2009.2032660

[23] Hawkins, R.E. and Burke, M.D. (1989) Person Monitoring System. US Patent 4814751.

[24] Lee, R.-G., Chen, K.-C., Hsiao, C.-C. and Tseng, C.-L. (2007) A Mobile Care System with Alert Mechanism. IEEE Transactions on Information Technology in Biomedicine, 11, 507-517. http://dx.doi.org/10.1109/TITB.2006.888701

[25] Lin, Y.-H., Jan, I-C., Ko, P.C.-I., Chen, Y.-Y., Wong, J.-M., Jan, G.-J., et al. (2004) A Wireless pda-Based Physiological Monitoring System for Patient Transport. IEEE Transactions on Information Technology in Biomedicine, 8, 439447. http://dx.doi.org/10.1109/TITB.2004.837829

[26] Peddicord, H.Q. and Tabor, K.A. (2002) In-Home Patient Monitoring System. US Patent 6402691.

[27] Tacklind, C.A., Sanders, M.H. and Walne, G.B. (1996) System for Monitoring and Reporting Medical Measurements. US Patent 5549117.

[28] Tacklind, C.A., Sanders, M.H. and Walne, G.B. (1998) System for Monitoring and Reporting Medical Measurements. US Patent 5704366.

[29] Monk, S. (2012) Programming Arduino. McGraw-Hill Companies, USA. 